\title{
Rare case of deep pelvic retroperitoneal mature cystic teratoma
}

\author{
Shalini Mahana Valecha*, Maimoona Ahmed, Mona Oswal, \\ Manisha Gandhewar, Prajakta Shende
}

Department of Obstetrics and Gynaecology, Employees State Insurance Post Graduate Institute of Medical Sciences and Research\& Model Hospital, Central Road, MIDC, Andheri East, Mumbai-400093, India

Received: 25 June 2013

Accepted: 11 July 2013

*Correspondence:

Dr. Shalini Mahana Valecha,

E-mail: shalini.mahana@gmail.com

(C) 2013 Valecha SM et al. This is an open-access article distributed under the terms of the Creative Commons Attribution Non-Commercial License, which permits unrestricted non-commercial use, distribution, and reproduction in any medium, provided the original work is properly cited.

\begin{abstract}
Mature cystic retroperitoneal teratomas are typically rare childhood tumours. Less than $20 \%$ of these occur in adults more than 30 yrs of age. Our adult patient presented with such a tumour, which had grown to a disproportionately large extent. It was deeply embedded in the true pelvis extending laterally to the pelvic wall and inferiorly till the ischiorectal fossa and was adherent to the surrounding structures displacing all. A provisional diagnosis was made after MRI scan and patient was posted for exploratory laparotomy. After extensive blunt and sharp dissection, the cyst wall could be separated from the surrounding structures and successfully excised. Histopathology confirmed the diagnosis. Being such a rare tumour, it is essential to have a high degree of suspicion in such cases that can be supported by advanced imaging modality. Early diagnosis and complete surgical removal are the mainstay of management that provide an excellent prognosis for such patients.
\end{abstract}

Keywords: Mature Teratoma, Cystic, Retroperitoneal, Adult

\section{INTRODUCTION}

Teratomas are congenital tumours containing derivatives of all three germ layers generally arising from gonads, rarely in extragonadal sites. Primary retroperitoneal teratomas account for $1-11 \%$ of all retroperitoneal neoplasms and are childhood tumours. Less than $20 \%$ of these patients are over 30 yrs of age. ${ }^{1}$ Early diagnosis and surgery are the mainstay of treatment.

Here we describe a rare case of a deeply embedded pelvic retroperitoneal mature cystic teratoma in an adult patient, successfully removed surgically.

\section{CASE REPORT}

Mrs. XYZ, a 38 yr old lady came with complaints of severe abdominal pain which was present on and off for 2 months but increased in severity since 3 days. Patient complained of chronic constipation. She had mild tachycardia and mild pallor. Abdomen was soft with generalised tenderness. Speculum could not be introduced due to extreme vaginal fullness from an extensive and deep pelvic mass. On per vaginal examination, a large $8 \times 10 \mathrm{~cm}$ mass was felt in the paravaginal region, extending in the presacral, pararectal area upto lateral pelvic wall, fluctuant, tender. Ultrasonography showed ovarian tumour with torsion. As clinical picture did not correlate, MRI was done. MRI showed a large $10 \times 10 \mathrm{~cm}$, thin walled cystic lesion in the deep, paravaginal and pararectal area filled with thick proteinaceous substance (Figure $1 \& 2$ ). Patient was posted for emergency laparotomy. Intra-op a large cyst was noted containing clay coloured, putty like material in paravaginal, pararectal, presacral space extending upto lateral pelvic wall, obturator foramen and inferiorly ischiorectal fossa, densely adherent to all surrounding structures (Figure 3). Cyst was drained and wall removed with great difficulty by extensive blunt and sharp dissection. Histopathology revealed Mature Cystic Teratoma (Figure $4 \& 5$ ). 


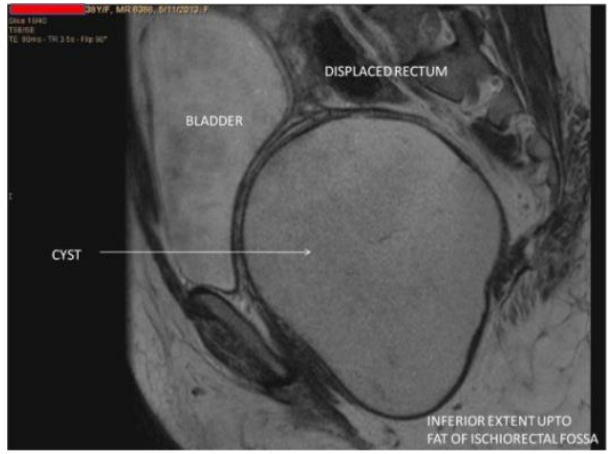

Figure 1: MRI showing deep location, content and extent of cyst.

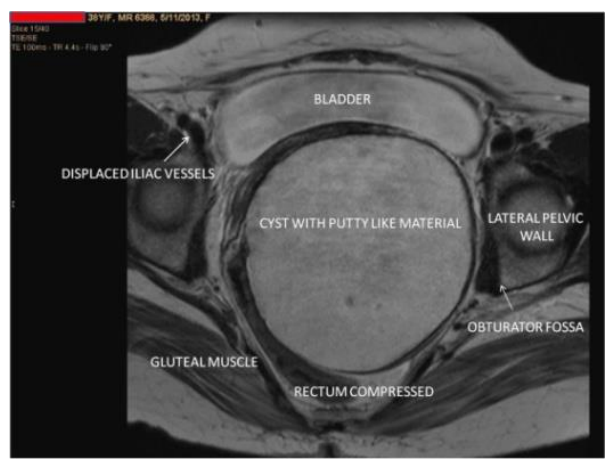

Figure 2: MRI showing lateral extent of cyst with displacement and compression of surrounding structures.

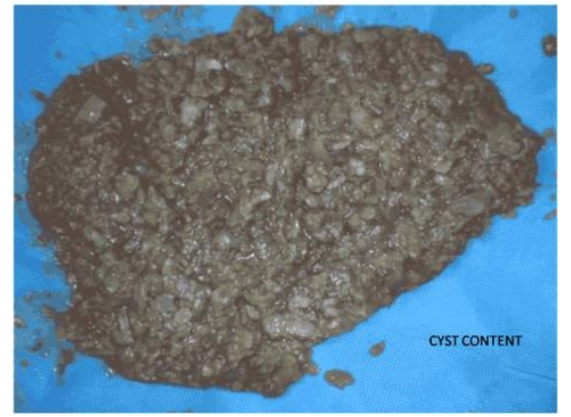

Figure 3: Gross picture of cyst contents.

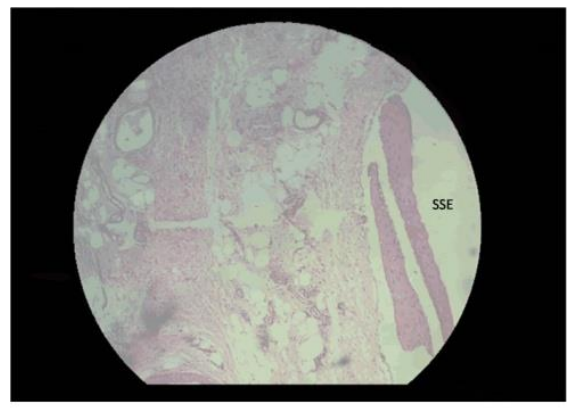

SSE-STRATIFIED SQUAMOUS EPITHELUUM

Figure 4: Histopathology of cyst wall showing stratified squamous epithelium (epidermal origin).

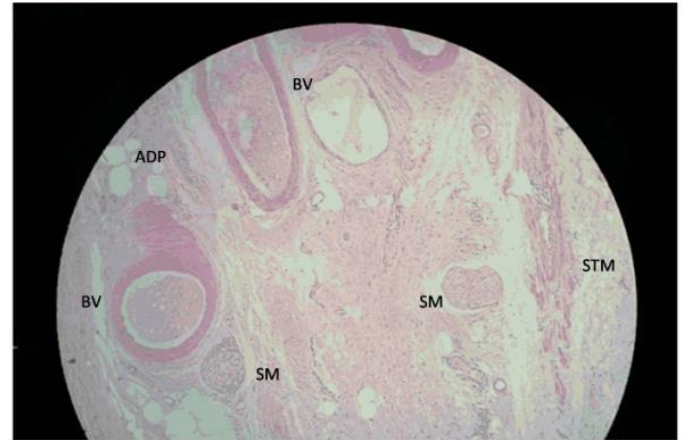

BV-BLOOD VESSEL, ADP-ADIPOSE TISSUE, SM- SMOOTH MUSCLE, STM - STRIATED MUSCLE

Figure 5: Histopathology showing various elements of mesodermal and endodermal origin.

\section{DISCUSSION}

Teratomas are tumours arising from pluripotential embryonal cells. The migratory property of germ cells explains their occurrence in extragonadal sites, generally along the midline. ${ }^{1}$ The deep pelvic and lateral extension in this patient is a rarest of rare occurrence.

Retroperitoneal teratomas remain asymptomatic as this space is extensive enough to allow free growth. When the tumour grows large enough and compresses surrounding structures, patients have abdominal distension, pain and pressure symptoms. Acute abdomen as a presentation is rare as seen here. ${ }^{2}$

Macroscopically teratomas are classifieds into cystic and solid. Cystic teratomas are typically benign in nature whereas solid are malignant. ${ }^{3}$

The differential diagnosis can be divided into neoplastic (lymphangioma, mucinous cystadenoma, epidermoid cyst) and non-neoplastic (lymphocoele, urinoma, hematoma). As clinical implications and therapeutic strategies differ for all, it is important to differentiate between these masses. ${ }^{4}$

Among imaging modalities, CT scan gives specific information on the fat, proteinaceous fluid, calcification, tumour extent and cyst wall. ${ }^{4}$ MRI scan is superior to CT and USG for demonstrating relationship with adjacent structures and local spread.

Goal of treatment is complete surgical removal. If contiguous spread hasn't occurred, the cure rate is high. ${ }^{7}$ However as it is possible that histologically mature teratomas may take a malignant clinical course, careful follow-up is necessary for such cases. ${ }^{8}$

\section{REFERENCES}

1. Gschwend J, Burke TW, Woodward JE, Heller PB. Retroperitoneal teartoma presenting as abdominalpelvic mass. Obstet Gynecol 1987;70:500-2. 
2. Taori K, Rathod J, Deshmukh A, Singh S et al. Primary extragonadal retroperitoneal teratoma in an adult. The British Journal of Radiology 2006;79:e120-e122.

3. Rai PK, Nayak B, Seth A. Extraordinary large primary retroperitoneal cystic teratoma: An extremely rare neoplasm. African Journal of Urology 2012;18:180-182.

4. Yang DM, Jung DH, et al. Retroperitoneal Cystic Masses: CT, Clinical, and Pathologic Findings and Literature Review. Radiographics 2004;24:1353-65.

5. Bellin MF, Duron JJ, Curet PH, Dion-Voirin E, Grellet J. Primary retroperitoneal teratoma in the adult: correlation of MRI features with CT and pathology. Magn Reson Imaging 1991;9:263-6.

6. Choi BI, Chi JG, Kim SH, Chang KH, Han MC. MR imaging of retroperitoneal teratoma: correlation with CT and pathology. J Comput Assist Tomogr 1989;13:1083-6.

7. Muguti GI, et al. Retroperitoneal mature cystic teratoma in an infant. Cen Afr J Med 1997;43:274276.

8. Jian-Shiu Chen, Ying-Huei Lee, Jong-Khing Huang. Primary Retroperitoneal Cystic Teratoma: A Case Report. J Urol R.O.C. 2000;11:82-5.

DOI: $10.5455 / 2320-1770$. ijrcog20130946

Cite this article as: Valecha SM, Ahmed M,

Oswal M, Gandhewar M, Shende P. Rare case of deep pelvic retroperitoneal mature cystic teratoma. Int J Reprod Contracept Obstet Gynecol 2013;2:460-2. 